ROSANA MACHIN BARBOSA, doutora em Sociologia pela Universidade de São Paulo, é professora-visitante na Universidade Federal de São Paulo, Departamento de Medicina Preventiva. E-mail: rosana.machin@uol.com.br

\section{Liberalismo político no pensamento de Carl Schmitt: amigo ou inimigo?}

Bernardo FERREIRA. O risco do político: crítica ao liberalismo e teoria politica no pensamento de Carl Schmitt. Belo Horizonte/Rio de Janeiro, Editora da UFMG/Iuperj, 2004. 339 páginas.

Pedro H. Villas Bôas Castelo Branco

O Risco do político de Bernardo Ferreira, publicado em 2004, representa uma original contribuição dentro e fora do Brasil. Embora o autor afirme que seu trabalho incorpore algo do caráter assistemático da produção intelectual de Carl Schmitt, a leitura do livro oferece ao leitor uma exposição metódica, ordenada e clara de como a teoria política de Schmitt se constrói mediante sua polêmica com o pensamento liberal. Bernardo Ferreira examina a crítica que o autor alemão faz aos principais conceitos e representações da ordem liberal durante o período da República de Weimar, precisamente, entre 1919 e 1933. A crítica ao liberalismo, elaborada antes de Schmitt aderir ao nazismo em 1933, teria sido decisiva para o autor forjar seu conceito do político. Temas como a secularização, a análise da modernidade, a crise do Estado, o niilismo, a teologia política, a técnica, a crítica do racionalismo da Aufklärung, a realização do direito, estão intimamente ligados à crítica ao liberalismo.

O estudo de Bernardo Ferreira consiste numa análise textual que compreende os escritos de Schmitt entre 1919 e 1933. O recorte histórico obedece a certos critérios. Em 1919 é publicado o livro de Schmitt Politische Romantik (Romantismo político) e, a partir de 1933, suas idéias teriam se convertido numa apologia cega das idéias nacionalsocialistas. A adesão de Schmitt ao nazismo em 1933 teria o levado até 1937 à tentativa de instituir uma ordem jurídica e política cuja base seria a idéia de uma comunidade racialmente homogênea. Curiosamente, antes de 1933, ao longo do período conhecido pelos debates de Weimar, Schmitt não só chamava a atenção para a ameaça nazista, como também buscava mostrar a inviabilidade de 
se fundar um regime político a partir de princípios raciais e homogêneos. O recorte histórico de Bernardo Ferreira, ao deixar de lado os trabalhos que sustentavam idéias nazistas, busca imunizar a produção intelectual de Schmitt. A decisão metodológica pela imunização dos escritos de Schmitt permite uma análise de sua teoria política e jurídica antes de ingressar no partido nazista, portanto livre das desprezíveis posições que seriam sustentadas pelo autor posteriormente. Contudo, Bernardo Ferreira faz concessões à sua própria delimitação cronológica e utiliza dois livros posteriores a 1933, Positionen und Begriffen (Posições e conceitos) de 1940 e Der Leviathan in der Staatslehre des Thomas Hobbes (O Leviatã na teoria do Estado de Thomas Hobbes) de 1938. A justificativa de que ambos os livros de Schmitt retomam a crítica do liberalismo parece revelar a dificuldade de saber a partir de quando se poderia então retomar a crítica do liberalismo de Schmitt, tendo em vista que são obras posteriores ao seu afastamento do III Reich em 1936 por ordens de Hitler.

Entre outras razões, o recorte histórico orienta-se pela suspeita de que Schmitt crítica ao liberalismo. No referido texto, como em nenhum outro, Schmitt teria se no texto sobre romantismo político teria apresentado um dos aspectos principais de sua empenhado em focalizar o "núcleo metafísico" dos conceitos e das idéias do liberalismo e suas instituições políticas. O núcleo metafísico do liberalismo corresponderia aos fundamentos e às conseqüências últimas das instituições liberais que Schmitt investiga por meio de um tratamento extremo da estrutura do pensamento liberal. Uma das características do referido núcleo metafísico liberal manifestar-se-ia na relação entre política e história: por meio do desenvolvimento histórico seria possível superar a política. A filosofia da história liberal teria difundido a crença no progresso gradual e na realização de uma paz vindoura que ocorreria neste mundo. A despeito de a teoria liberal apresentar o progresso e o conseqüente alcance da paz como fenômenos imanentes a este mundo, Schmitt mostra o fundamento teológico e metafísico de tal concepção liberal. Isto fica claro a partir do momento em que o fim último de todas as coisas deixa de ser representado por Deus e passa a residir no indivíduo. $\mathrm{O}$ indivíduo liberal burguês seria a versão seculariza- da de Deus. Ao elevar o indivíduo à condição suprema da ordem social, o liberalismo levaria à fragmentação da experiência histórica, dos fundamentos tradicionais, de qualquer medida objetiva que fosse capaz de dar direção à conduta humana. A centralidade atribuída ao sujeito liberal impediria que qualquer terceiro decidisse a respeito da vida de um indivíduo livre. A autonomia privada seria resguardada pela aparente substituição de decisões políticas por medidas econômicas e administrativas. A despolitização e a neutralização da vida política estariam ligadas ao funcionamento autônomo e pacífico das várias esferas da vida como a economia, a moral, a ciência etc. A idéia de uma ordem auto-regulada pela liberdade econômica e por normas racionais seria apta a realizar a paz. A adesão aos princípios liberais teria furtado o conteúdo da política, transformando os conceitos e as idéias da política em formas vazias. Isto significa que o liberalismo despolitiza e neutraliza qualquer forma de existência política, pois suas idéias buscam ocultar o conflito presente na vida pública. A difusão da crença na eliminação do conflito, na ausência de antagonismos na vida política por meio do progresso econômico, na normalidade e na auto-suficiência da ordem, seriam algumas das causas que levariam à construção de um mundo capaz de superar os conflitos. Superar a dimensão do conflito político que caracteriza as relações entre os homens significa superar a necessidade de tomar decisões. As idéias e os conceitos liberais teriam neutralizado o caráter político da experiência histórica.

O autor do Risco do político observa que Schmitt compreende o liberalismo como "pensamento póstumo", concebido na tensão das circunstâncias da vida histórico-política para enfrentar um inimigo: o Estado absolutista. Contudo, após vencer o inimigo, as idéias liberais e suas instituições teriam esmorecido. A distância entre seus princípios constitutivos e a realidade histórica com a qual se deparava, entre outras razões em virtude do surgimento da democracia de massas, teria levado o liberalismo à incapacidade de se adequar à "experiência política", e, conseqüentemente, de orientá-la. A ordem liberal teria sido destituída de sua eficácia histórica, mas sua estrutura teria se conservado viva como uma espécie de fantasma. Bernardo Ferreira observa que, de 
acordo com Schmitt, o liberalismo teria adquirido sua força de permanência da filosofia da história do século XVIII. Dela teria tomado de empréstimo uma perspectiva mais ampla dirigida para uma vida melhor e uma maior capacidade de persuasão. Na esteira da filosofia da história do século XVIII, chamada por Schmitt, na obra Era das neutralizações e despolitizações, de estágio humanitário-moral, o liberalismo ancorado na imagem de uma "neutralidade auto-regulada" amalgamava-se a uma poderosa idéia de progresso. Ao pintar o retrato de uma marcha histórica orientada pelo telos da paz vindoura, o liberalismo forjava a imagem de um processo histórico capaz de subtrair a raiz dos conflitos políticos-sociais. Na representação do mundo liberal a história transcenderia à política porque a substância política do presente é esvaziada em nome da realização futura da ordem pacífica. Logo, a filosofia da história liberal ao acreditar na supressão de casos extremos ou situações excepcionais de uma dada ordem acabava evitando a tomada de uma decisão política. A crença na realização de uma ordem pacífica e da existência de um Estado neutro tornaria irrelevante a necessidade de uma decisão política, isto é, a decisão acerca do conflito.

De acordo com Bernardo Ferreira duas idéias centrais no pensamento de Schmitt devem ser mencionadas. A primeira define como momento crítico da história de um conceito a situação na qual o adversário desde conceito deixa de existir. A segunda relaciona-se à energia de conceitos e fórmulas que se mantêm acesas mesmo depois do colapso do inimigo. Depreende-se a parir daí que o liberalismo, mesmo depois de vencer o conflito contra o Estado absolutista, manteria viva a noção de uma filosofia da história progressista que, no século XIX, assumiria a idéia, não mais de um avanço humanitário-moral, mas de progresso econômico capaz de esvaziar os conflitos políticos no caminho da paz. Isto se torna claro na conferência de Era das neutralizações e despolitizações, analisada em Risco do político. Bernardo Ferreira apresenta e comenta a exposição de Carl Schmitt sobre o percurso do "espírito europeu", que teria se deslocado do século XVI ao século XX. A partir do século XVI teria ocorrido um movimento ininterrupto de uma "esfera central" para outra: do século XVI teológico para o século XVII metafísico, passando pelo
XVIII humanitário-moral, até o XIX econômico. No século XX teria ocorrido o deslocamento do estágio econômico para o técnico. O autor do Risco do político interpreta os movimentos apontados por Schmitt como uma "anti-filosofia da história". A despolitização das lutas teológicas e a busca de uma esfera neutra na metafísica do século XVII constituem um passo decisivo no processo de secularização, característico da modernidade ocidental. O deslocamento para uma área neutra ocorre em virtude da incerteza resultante da desestruturação de uma ordem ancorada num suporte transcendente. Bernardo Ferreira comenta que os passos no caminho da neutralização na transição do teológico ao metafísico somente fazem sentido quando se compreende o processo de secularização. Este poderia ser caracterizado como a substituição regular ou a sucessão repetida de oposições que se objetivam por intermédio da estruturação e da reestruturação do antagonismo amigo/inimigo e seus movimentos neutralizantes.

O Risco do político ressalta a idéia de que a passagem de uma região central (Zentralgebiet) para outra é caracterizada como processo de secularização, e que pode ser pensada sob dois aspectos. O primeiro é associado ao gradual desgaste dos fundamentos transcendentes da realidade e a reviravolta da ontologia tradicional. Na esteira da interpretação de Karl Löwith, sustenta Ferreira que na modernidade a condição de possibilidade da ordem política substancial depende de um suporte metafísico ou transcendente. Contudo, não deixa de observar o segundo aspecto do processo de secularização como a sucessão de imagens metafísicas do mundo. A troca de imagens religiosas por noções mundanas e seculares não eliminaria a estrutura metafísica da vida espiritual. Assim como Zentralgebiet, no afã de neutralizar o caráter contingente da existência política, se reconstitui em conformidade com uma área central, a estrutura metafísica da vida espiritual se reatualizaria. Essa reatualização, no entanto, assumiria uma mudança de sentido: um deslocamento para uma representação imanente da realidade. Portanto, em todos os estágios, inclusive no da técnica, há uma esfera espiritual - justamente por isso Schmitt não considera a técnica uma "mecânica sem alma" - que se movimenta em meio a um complexo de crenças. O duplo aspecto do processo de secularização carac- 
terizar-se-ia, por um lado, pelo desgaste das representações religiosas da realidade e a conseqüente erosão da "ontologia tradicional"; por outro, por uma sucessão de imagens metafísicas do mundo. Nesse sentido, a esfera espiritual sempre manterá uma estrutura metafísica, independentemente de seu gradual deslocamento da transcendência das representações religiosas para a imanência das representações da tecnicização da realidade. O deslocamento do plano de salvação de Deus para a salvação da "neutralidade" da técnica não remove a estrutura metafísica da esfera espiritual. A secularização estaria associada a um processo que resultaria na divinização da técnica. Esta, devido a sua cegueira cultural, seria incapaz não só de criar uma organização social, mas também de dirigi-la. Ao privilegiar os meios em detrimento dos fins, a técnica, estado puro de imanência, seria uma fonte de niilismo. Nessa perspectiva, o processo de secularização revelar-se-ia de forma mais intensa no seu ponto de chegada: no âmbito da pura imanência da técnica, caracterizado pelo automatismo de processos e pela incapacidade de produzir significados.

A orientação escatológica imanente ao mundo liberal é fundada na fé de um homem que se cria a si mesmo. Contudo ao fazê-lo fora das possibilidades de sua existência, o homem torna-se um ser inescrutável, mantém sua ontologia da periculosidade, mas seus desígnios e sua produção de sentidos se tornam absolutamente ininteligíveis. Sua salvação torna-se mais incerta. Um dos pontos fundamentais da teologia política é a relação entre fé e ação política. Uma relação que Schmitt resgata mediante um conceito de secularização ligado a uma teologia política na qual busca uma reorientação escatológica da fé, sem, no entanto, dissociá-la da experiência política.

Ao investigar a crítica de Schmitt ao liberalismo político, Bernardo Ferreira descortina o caráter polêmico que o pensamento assume em seus trabalhos. A imagem de mundo elaborada por Schmitt seria proveniente do papel que o liberalismo desempenha em sua reflexão teórica. O liberalismo é elevado à condição extrema de inimizade, e é justamente este procedimento que o torna inteligível. Da oposição radical ao liberalismo derivaria justamente a possibilidade de problematizá-lo e desvendá-lo na sua dimensão política concreta que buscava ocultar. Não só, a forma polêmica do pensamento ou o ato de pensar contra daria sentido a uma elaboração normativa capaz de orientar a ação humana sem escamotear à contingencialidade e a indeterminação das relações políticas. Schmitt formula sua posição normativa à medida que elabora um quadro conceitual do liberalismo e suas instituições políticas. Por isso, observa o autor do Risco do político, que Schmitt, ao perscrutar conceitos políticos, não se atém apenas à descrição da realidade concreta dos conceitos políticos, mas também à sua dimensão prescritiva. Os livros e os artigos redigidos por Schmitt transitam entre a abordagem "realista" dos conceitos políticos, buscando apresentá-los tal como são, e uma postura normativa, que indica como devem ser ou como devem orientar a conduta humana. A apresentação desta tensão que caracteriza os trabalhos de Schmitt é alcançada pela afirmação da natureza conflitante e, portanto, polêmica do político. Mas o leitor não deve perder de vista que Schmitt incorpora esta tensão do conflito às premissas de seu pensamento, elevando a atividade de pensar a uma conduta sempre polêmica. Isso não define só um estilo, mas a possibilidade de pensar politicamente o que é entendido como político. Em outras palavras, a fim de conhecer a dimensão do político que se manifesta no liberalismo, é preciso levar em conta a idéia da média extrema na qual se evidencia o ponto da dissociação entre amigo e inimigo. Assim, pode-se perceber que o mundo liberal não é um mundo pacífico da liberdade, da técnica, do consenso, da livre concorrência econômica entre indivíduos governados por normas racionais. A internalização cognitiva do conflito confere a possibilidade de apreender a idéia de medida, o que significa captar a situação extrema da tensão concreta na qual se revela, por exemplo, o poder fático de mando que homens exercem sobre homens.

Creio que a principal contribuição do Risco do político resida no estatuto epistemológico que ocupa a inimizade na reflexão política de Schmitt. A conhecida contraposição entre amigo e inimigo não diria apenas respeito ao grau de intensidade extremo da associação ou da dissociação de um determinado agrupamento humano em razão da potencialidade sempre presente da guerra ou da eliminação física de outro. Na reflexão teórica de Schmitt, a distinção entre amigo e inimigo tam- 
bém representaria o papel de uma condição de possibilidade adequada a examinar o limite, o alcance e a constituição de saberes pertinentes à filosofia política. Bernardo Ferreira mostra que de acordo com Schmitt todas as palavras, os conceitos e as representações políticas apresentam um sentido polêmico quando o antagonismo de grupos - devido a guerras ou revoluções - alcança o caso extremo da distinção entre amigos e inimigos. Agrupamentos humanos atribuem sentidos às palavras, aos conceitos e às representações políticas no momento extremo do conflito em que se manifesta a possibilidade da guerra. O núcleo das coisas apenas se torna possível a partir de uma posição extrema. A intensidade extrema que dissocia homens em amigos e inimigos não é apenas a medida do político que dá sentido à conduta humana, mas é também a condição de possibilidade de todo o pensamento político.

PEDRO H. VILLAS BÔAS CASTELO BRANCO é doutorando na área de Ciência Política do Instituto Universitário de Pesquisas do Rio de Janeiro - Iuperj. E-mail: pvillasboas@iuperj.br 